\title{
CLINICAL PRACTICE IN OBSTETRICS AND GYNECOLOGY IN THE CONTEXT OF THE IMPLEMENTATION OF A COMPETENCY-BASED APPROACH TO THE ORGANIZATION OF EDUCATION OF MODERN STUDENTS
}

\author{
Nataliia Drohomyretska
}

Ivano-Frankivsk National Medical University, Ivano-Frankivsk, Ukraine

natalya.vl@ukr.net

\begin{abstract}
The article shows the role of clinical practice in Obstetrics and Gynecology in the context of the implementation of a competency-based approach to the organization of education of modern students. The indisputable advantages of the orientation of the educational process onto the achievement of professional competencies for the training of competitive specialists with flexible practical-meaningful thinking are determined.

Priority in the system of medical education is the development of new approaches, methods and forms of training in order to form readiness for the professional activity of a medical specialist. The efficiency of algorithmization and pedagogical potential of the casemethod in the structure of clinical practice teaching is proved.
\end{abstract}

Key words: clinical practice; Obstetrics and Gynecology; competency-based approach; case-technology.

In recent years, the requirements for the quality of knowledge of the future professionals have increased significantly. There is a necessity to develop qualitatively new teaching methods that would allow deeper implementation of the acquired theoretical knowledge in practice. Competencybased approach in higher medical education involves ensuring the orientation of the educational process to achieve certain, integrated in its content, educational outcomes, which are general and special (clearly related to the acquired specialization, professional) competencies. This approach has undeniable advantages in training competitive professionals with flexible practical-meaningful thinking. The development of the system of higher medical education on the basis of the competency-based approach involves the introduction of new educational technologies and methods of medical students' training, which will be the tools for the formation of these competencies. It is becoming increasingly clear that modern higher medical education is moving away from the informative paradigm of the study, focused on the knowledge transfer, skills and abilities formation, and moves to the competence, based on the generation of ability to master the future doctor profession. Therefore, the priority in the development of modern higher medical education should be the coexistence of two learning strategies - traditional and innovative, i.e., the formation of the readiness of the medical student to dynamic changes in society through the development of various forms of clinical thinking and personal development [1].

The main purpose of clinical practice is to create conditions and organization of the educational environment helping identify the professional readiness and ability of students to implement knowledge of specialized disciplines in the professional activity.

The tasks of clinical practice are aimed at establishing and strengthening the connection between theoretical knowledge and practice; formation of professionally necessary skills and abilities to provide qualified medical care; making independent decisions, developing the necessity for selfeducation, systematic updating of their own knowledge and the ability to use it in practice.

Skills in higher medical education are understood as professional actions that become automated through repetitions and training. Professional skills are relatively simple professional actions that compose the part of the skills structure. The term "skill" is understood as the ability to operate a complex system of theoretical knowledge and practical skills in solving fairly complex, atypical, non-standard professional problems. Skills are abilities and knowledge in action. In line with the introduction of competency-based approach of learning into the practice of the higher medical education, a relatively new concept of "abilities" is introduced, which is interpreted as a complex new formation of multilevel personality structure of the future specialist, based on the knowledge, skills, personally significant and professionally important qualities, which together provide a potential opportunity for a person to perform the future professional activities.

The elective course "Clinical Practice" is studied by fourth and fifth year students of the Faculty of Medicine and the Faculty of Training of Foreign Students and provides on the basis of fundamental knowledge of the professional discipline acquisition and exercise of practical skills in comprehensive assessment of the patient's condition, interpretation of research methods, substantiation of clinical diagnosis, study of algorithms of planned and emergency care for patients.

Types of student's learning activities, according to the curriculum of the discipline "Clinical Practice", are practical classes and independent work (including individual tasks). Classes are performed on the basis of the Departments of Therapeutic, Surgical, Obstetric-Gynecological and Pediatric profiles, consisting of 4 structural parts:

1) mastering the theoretical material provided by the content of the theme of the lesson, as well as algorithms for performing practical skills in the discipline;

2) demonstration by the teacher of methods of performance of the medical manipulations provided by a subject;

3 ) the work of students to exercise practical skills and abilities under the supervision of a teacher;

4) solving situational problems in accordance with the curriculum of the discipline.

The process of forming the competence of a medical student involves the following stages:

- the first one - the ability to reproduce knowledge without 
a hint, to solve problems according to the sample (algorithm). Determines the student's competence, to know how to...;

- the second one - the development of skills based on acquired knowledge, their application in standard, typical situations. Defines student's competence as skills development of ...;

- the third one - skills development, bringing skills to automatism in standard and non-standard situations. Defines the competence of a student as the development of skills in ...;

- the fourth one - the development of the student's ability to apply in professional activities his/her knowledge, skills, abilities, personally significant and professionally important qualities in their entirety. Defines student's competence as the ability to apply in activities... .

To achieve this goal at the Department of Obstetrics and Gynecology named after I.D. Lanovy in Ivano-Frankivsk National Medical University there were developed algorithms for practical skills for students in the discipline "Clinical Practice". The use of algorithms for performing practical skills not only increases the motivation of students to learn the material, but also optimizes the work of teachers. Strict sequence of algorithms plays an important role in the examination, as it streamlines the work, improves the level of professional mastery and practical skills of students at the educational stage, providing them with a more efficient, seamless and safe transition to practical medical activities.

The use of algorithms of practical skills allows students to repeatedly practice their performance not only during practical lessons while studying relevant themes, but also in modular ones. This helps to reduce the number of errors in the implementation of practical skills, as well as to increase the overall discipline and responsibility of students. The quality of practical skills should be one of the main criteria for the formation of professional competencies and, as a consequence, admission to work with real patients.

Based on the roles of teacher and student, as well as their interaction with each other during the educational process, teaching methods can be divided into three groups:

1. passive;

3. interactive.

Passive methods involve a form of interaction between teacher and students, in which the teacher is the main actor and manages the course of classes, and the students act as passive listeners, subject to the directives of the teacher.

However, the teacher must choose such forms of work that meet the purpose of the educational discipline. Based on the structure of the traditional practical lesson, the teacher must diversify its course by using different types of students' activities. With this approach, students are active participants of the educational process. They interact not only with the teacher, and on an equal footing, but also with each other.

One of the active forms of study is the problem-based one, which involves consistent and purposeful cognitive tasks that students solve under the guidance of the teacher, actively using new knowledge. Let's define the basic ways and techniques of creation of a problem situation: as a result of acquaintance of students with different interpretation of the same phenomenon, or fact; when the student is faced with new practical conditions for the use of new knowledge; the condition for its occurrence is also a contradiction between the theoretically possible ways to solve the problem and the practically achieved result, the task and the lack of its theoretical justification. The organization of active forms of learning involves modeling life situations, the use of roleplaying games, cooperative problem solving.

The main idea of interactive methods' use is to intensify the cognitive activity of students, actualization of basic knowledge, individualization of the educational process, providing opportunities for students to independently comprehend the acquired knowledge for its use in practice. They are aimed at active and deep mastering of the studied material, the development of the ability to solve complex problems. Innovative methods have also allowed changing the role of the teacher, who is not only a carrier of knowledge, but also a mentor who initiates the creative search for students [2].

When teaching the elective educational discipline "Clinical Practice" at the Department of Obstetrics and Gynecology named after I.D. Lanovy, the case-method of study is widely used.

Case-technology in medical education - is a series of specific clinical situations that are specifically designed on the basis of factual material for further analysis in the classroom. In the process of their consideration, students master teamwork, learn to analyze, make operational decisions, apply existing theoretical knowledge to solve practical problems. The main peculiarity of this method is the process of studying precedents, in other words, practical situations that have taken place in the past.

Situational tasks are a tool that greatly facilitates and improves the exchange of ideas in groups of students. Practical classes based on the method of situational tasks help learning the rules of discussions. During these discussions, each student participates in the study, analysis and comparison of different views, which leads to a more accurate understanding of the problem. Expressing opinions gives you the opportunity to feel own capabilities and strengthen them, which is very important for future medical professionals. Ideas, knowledge developed in the group help participants to be useful to each other.

This method makes it possible to develop student's independence of thinking, the ability to listen, and then take into account the alternative view and in a well-argued manner articulate their own. With the help of case-technology, students have the opportunity to both identify and improve their assessment, analytical skills, as well as learn to work in teams and find rational solutions to existing problems.

As an interactive method, case-technology evokes mostly positive emotions on the part of students, providing them with the opportunity to master theoretical knowledge and master practical skills. It affects the professionalization of future specialists, contributing to the formation of interest, positive motivation to study. At the same time, the casemethod in medical education also acts as an improvement of the teacher's way of thinking. One can say, that this is his/her specific paradigm that allows students to think, act differently, update their existing creative potential.

The teacher's activity when using the case-method includes two stages. The first one is a complex creative work on the formation of a case and questions for its analysis. It is performed outside the classroom, involves scientific-research 
and methodological activities of the teacher. The second one - is the teacher's work in the classroom, where he/she is responsible for creating such an intellectual atmosphere that would promote the exchange of students' own ideas, knowledge and experience, evaluates the contribution of students into the situation analysis [3].

Thus, the pedagogical potential of the case-method is much greater than that of traditional training methods. The teacher and the student constantly interact, choose forms of behavior, face each other, motivate their actions, argue their moral norms.

The case-method has a very wide educational potential. The variety of results which are possible while using it, could be divided into two groups: training and educational ones. The first ones - are related to the development of knowledge and skills, they may include: the development of new information, methods of data collection and analysis, the ability to work with medical records, the comparison of theoretical and practical knowledge. The second ones - are the results formed by the participants themselves of the interaction, realized personal learning goals: creating an author's product, achieving personal goals, increasing the level of professional competence, the emergence of experience in decision-making, action in a new situation.

\section{Conclusions}

1. For students trained at higher medical educational institutions, the acquisition of professional competencies is a necessary requirement for the formation of a young person as a specialist.

2. Clinical practice is one of the forms of organization of the educational process, which maximally contributes to the development of the student both as a person and future specialist, provides continuity and consistency of practical skills, abilities, professional self-improvement.

\section{References}

1. Filonenko MM. Methods of teaching in higher medical school on the basis of competency-based approach: methodical recommendations. Kyiv. 2016; 88 p.

2. Pavlyshyn HA, Bihuniak TV, Savaryn TV. Case-method of teaching in medical education. Medychna osvita. 2015;(3):67-69.

3. Pashchenko TM. Methods of creating study cases for the training of future skilled workers. ScienceRise. Pedagogical Education. 2015;(9/5):65-70.

Received: 21.04 .2021

Revised: 05.05.2021

Accepted: 17.05.2021 